\title{
An application of indirect model reference adaptive control to a low-power proton exchange membrane fuel cell
}

\author{
Yee-Pien Yang*, Zhao-Wei Liu, Fu-Cheng Wang \\ Department of Mechanical Engineering, National Taiwan University, Taipei, Taiwan, ROC \\ Received 5 December 2007; received in revised form 24 January 2008; accepted 24 January 2008 \\ Available online 6 February 2008
}

\begin{abstract}
Nonlinearity and the time-varying dynamics of fuel cell systems make it complex to design a controller for improving output performance. This paper introduces an application of a model reference adaptive control to a low-power proton exchange membrane (PEM) fuel cell system, which consists of three main components: a fuel cell stack, an air pump to supply air, and a solenoid valve to adjust hydrogen flow. From the system perspective, the dynamic model of the PEM fuel cell stack can be expressed as a multivariable configuration of two inputs, hydrogen and air-flow rates, and two outputs, cell voltage and current. The corresponding transfer functions can be identified off-line to describe the linearized dynamics with a finite order at a certain operating point, and are written in a discrete-time auto-regressive moving-average model for on-line estimation of parameters. This provides a strategy of regulating the voltage and current of the fuel cell by adaptively adjusting the flow rates of air and hydrogen. Experiments show that the proposed adaptive controller is robust to the variation of fuel cell system dynamics and power request. Additionally, it helps decrease fuel consumption and relieves the DC/DC converter in regulating the fluctuating cell voltage.
\end{abstract}

(C) 2008 Elsevier B.V. All rights reserved.

Keywords: PEM fuel cell; System identification; Model reference adaptive control

\section{Introduction}

Proton exchange membrane fuel cells, also known as polymer electrolyte membrane fuel cells, have the advantages of high power and energy density, low operation temperature, fast start-up, and higher efficiency, but still face many challenging technical hurdles, such as cost, size, weight, durability, reliability, and air, thermal, and water management [1-3]. In addition, fuel cells are subjected to various situations of time-varying load, during which the air-flow, gas pressure, temperature, humidity, and membrane hydration must be controlled over a wide range of operation. Typical fuel cell system operation requires prompt measurement of system states by a set of sensors, such as flow meters, thermocouples, pressure transducers, voltmeter, hall sensor, hydrogen detector, etc. These signals are typically fed back to a microprocessor that calculates proper control actions based on a specific control strategy that is executed by

\footnotetext{
* Corresponding author. Tel.: +886 2 33662682; fax: +886 223631755 .

E-mail address: ypyang@ntu.edu.tw (Y.-P. Yang).
}

various actuators, such as an air pump, a humidifier, solenoid valves, fan motors and safety devices.

The complex, nonlinear dynamics of fuel cell systems are usually approximately described by the principles of electrochemistry, fluid dynamics, and heat transfer in terms of physical parameters, material properties, and universal constants under various assumptions and constraints. The dynamic response of cell voltage and current involve reactant pressure and flow rate, local species concentration, and load electrical demands, which can vary rapidly enough that many assume these are instantaneous. On the other hand, fuel cell temperature and its regulation, humidity, cell hydration, as well as overall heat management processes are characterized by relatively slow dynamic response, as analyzed by Mueller et al. [4]. Many researchers have devoted themselves to developing and using steady-state models of PEM fuel cells, describing the relationships amongst physical variables through the Nernst equation, gas diffusion equation, and species concentration and polarization equations. Most recently, an increasing number of researchers have focused on dynamic models to describe the transient response of PEM fuel cell systems. Pukrushpan et al. [5] modeled transient dynamics with 
a set of first-order differential equations governing the air compressor, mass transportation, energy conservation of the reactant flows, and pressures in the cathode and anode. Ceraolo et al. [6] provided more precise partial differential equations to describe both static and dynamic behaviors of the PEM fuel cell, including gas diffusion, proton concentration, and mass transportation. In their spatial, time-dependent fuel cell model, Golbert and Lewin [7] included the dynamics of water condensation, evaporation, and generation, as well as quasi-steady-state temperature profile. Pathapati et al. [8] derived a dynamic model with the effects of charge double-layer capacitance, dynamics of flow and pressure, and mass/heat transient features of fuel cells, which predicted the transient response of cell voltage, temperature, gas flow rates, and pressure under a sudden change in load current. A highly dynamic PEM fuel cell stack model was proposed by Shan and Choe [9], which took into account the most influential property of temperature on the output performance and dynamics.

Although some researchers have proposed an effective model for system and control development $[4,10]$, the nonlinearity and time-varying characteristics still pose difficult problems for system identification and control. Simplified models, either linear or nonlinear, with nominal parameters are usually valid within a linear range of operation. Such models are usually used to investigate stability, sensitivity, observability, and controllability, before designing a controller. More practically, these parameters that vary with time and operating states are identified in real time to match system response with minimal errors. Therefore, adaptive control can serve as a feedback law to achieve control objectives subject to the variation of system parameters as well as external disturbances. Pukrushpan et al. [5] designed an observer-based feedback controller to protect the fuel cell stack from oxygen starvation during the change of current command, using the linear quadratic technique based on the linearized state-space model. Paradkar et al. [11] integrated a linearized PEM fuel cell model into a power plant, and simulated a load frequency control problem by an optimal controller based on the disturbance accommodation control theory. Schumacher et al. [12] employed a fuzzy controller to manage humidity by adjusting the fan voltage for supplying air to a miniature PEM. Jurado and Saenz [13] noted that their proposed adaptive control strategy was able to stabilize a hybrid fuel cell and turbine system subject to system parameter variations and external disturbances. Tekin et al. [14] provided a fuzzy proportional-derivative (PD) controller plus integral (I) controller to adjust the air-flow rate of a $5 \mathrm{KW}$ PEM fuel cell. It was found that the ratio between the consumed energy by the motor-compressor group and the energy delivered by the fuel cell was greatly reduced. Woo and Benziger [15] applied a PID controller to regulate the output current of a single-cell PEM fuel cell by controlling the flow rate of hydrogen, while the full utilization of hydrogen was achieved with 30\% stoichiometric excess on the oxygen.

Recently, Meyer and Revankar [16] surveyed the controloriented models and control strategies of PEM fuel cell systems. The researchers indicated that future attempts to develop nonlinear multi-input multi-output systems must be important over the entire operating range in order to seek reduced reactant usage under various power demands. Methekar et al. [17] proposed a linear multivariable model for controlling the average power density and solid temperature of a PEM fuel cell to avoid oxygen starvation. The selected input variables were the inlet molar flow rate of hydrogen, the inlet molar flow rate of oxygen, the inlet flow rate of coolant, and the inlet gas temperatures of anodes and cathodes. These researchers simulated the order reduction from a distributed parameter model to a set of first- or second-order transfer functions, by which the PI-controller-based power and solid temperature control loops were constructed.

The authors have also presented a preliminary study of system identification, and robust and adaptive controls of a low-power PEM fuel cell $[18,19]$. This paper extends the previous singleinput single-output (SISO) adaptive control to a multivariable configuration of indirect model reference adaptive control. Both the air and hydrogen flow rates are used to regulate cell voltage and current according to the updated information of the external load and system dynamics.

\section{Material and methods}

\subsection{Fuel cell specifications}

The fuel cell stack in use consists of 15 cells with an active area of about $50 \mathrm{~cm}^{2}$, as shown in Fig. 1. The cells are connected with a pre-treated membrane (Nafion ${ }^{\circledR} 112$ ) by hot press for optimum conditions, and are electrically connected in series with catalyst layers where the platinum coating is about $0.2 \mathrm{mg} \mathrm{cm}^{-2}$ at the anode and $0.4 \mathrm{~m} \mathrm{~cm}^{-2}$ at the cathode. The gas separator plates are made of the graphite material (TOYO TANSO, Japan) treated to become gas impermeable; each is as large as $160 \mathrm{Lmm} \times 50 \mathrm{Wmm} \times 2 \mathrm{Tmm}$ with two fins on each side, and each fin has a size of $160 \mathrm{Lmm} \times 15 \mathrm{Wmm} \times 1 \mathrm{Tmm}$. This design is so similar to the cooling fins of internal combustion engine that it increases the cooling surface and improves the cooling efficiency. In addition, the hydrogen flow field consists of a serpentine pattern of parallel double-channels, and the airflow field consists of a straight pattern of parallel multi-channels and ribs in an active area of $40 \mathrm{~mm} \times 130 \mathrm{~mm}$.

The rated and peak power outputs of the fuel cell are $117 \mathrm{~W}$ at $9 \mathrm{~V}$ and $124 \mathrm{~W}$ at $7.9 \mathrm{~V}$, respectively. The maximum fuelto-electricity efficiency that the fuel cell can achieve is about

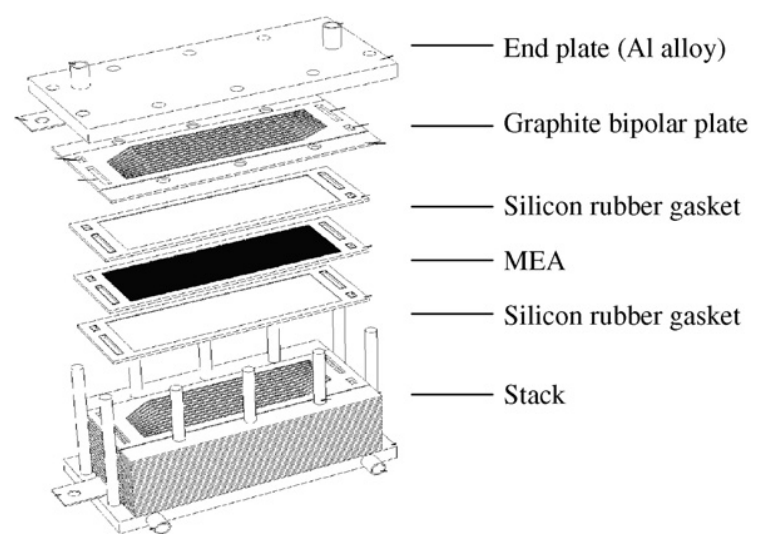

Fig. 1. $100 \mathrm{~W}$ fuel cell stack. 


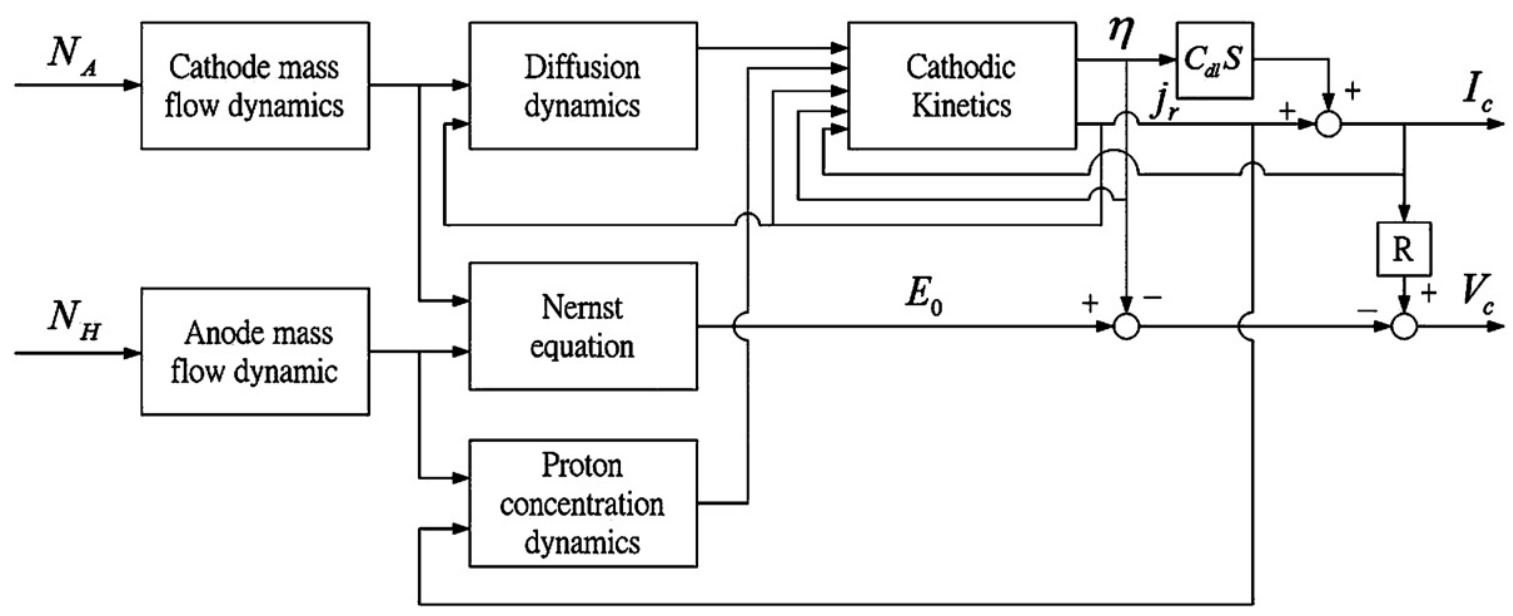

Fig. 2. PEM fuel cell system dynamics.

$37 \%$ on a lower heating value (LHV) under the dry $\mathrm{H}_{2}$ /air and humidification-free conditions. The fuel cell system was a prototype from Delta Electronics. The whole system includes an individual temperature control loop, water management loop, and flow control loop. This paper intends to replace the flow control loop using adaptive control while keeping the others unchanged. The flow rate of natural air is adjusted by an air pump, while the flow rate of hydrogen is regulated by a solenoid valve.

\subsection{Fuel cell system model}

In order to develop the control strategy of the low-power fuel cell, the dynamic models from the previous studies are integrated to describe the mass and heat transfer in flow channels, Nernst equation, cathode gas diffusion, cathode kinetics, and proton concentration dynamics [6,20-23]. From modern control theories [24], the control-oriented fuel cell system block diagram can be approximated as a two-input two-output system, as shown in Fig. 2. Equipped with additional balance-of-plant (BOP) components, such as an air pump and hydrogen valve, the fuel cell system can be simply reduced to a standard block diagram, as shown in Fig. 3.

From the system viewpoint, the hydrogen at a certain pressure is fed by a solenoid valve whose dynamics are denoted by the

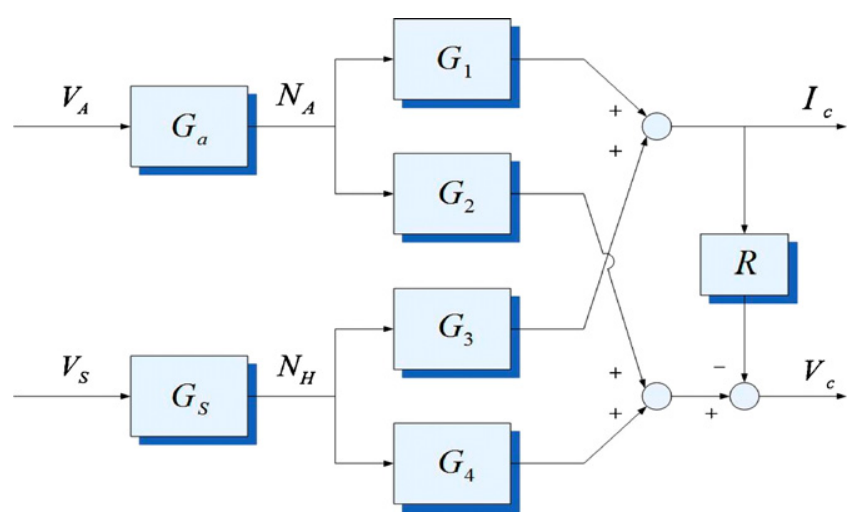

Fig. 3. Approximate fuel cell system block diagram. block $G_{\mathrm{S}}$ that describes the relationship between the hydrogen flow rate $N_{\mathrm{H}}$ and valve voltage $V_{\mathrm{S}}$. On the other hand, air at the standard atmosphere of 1 bar is often transported by an air pump to provide oxygen to the cathode, whose dynamics are denoted by the block $G_{\mathrm{a}}$ that describes the relationship between the airflow rate $N_{\mathrm{A}}$ and air pump voltage $V_{\mathrm{A}}$. The coupled blocks $G_{i}$, $i=1,2,3,4$, describe the relationships between the cell current $I_{\mathrm{c}}$ and cell voltage $V_{\mathrm{c}}$, and the air-flow rate $N_{\mathrm{A}}$ and hydrogen flow rate $N_{\mathrm{H}}$, where $R$ denotes the internal resistance of the fuel cell. It is noticed that the temperature and humidity of air and hydrogen are not managed in this research, but are regarded as two dependent states of the fuel cell. Assuming that the fuel cell is operated at a certain operating point, the six blocks can be linearized as transfer functions of finite orders and time-varying coefficients. These coefficients are implicit functions of state variables, such as temperature, membrane hydration, reactant pressure, gas concentration, etc., which directly affect cell voltage, current density, and the overall performance of the fuel cell. When the air pump voltage and the hydrogen valve voltage are regarded as input variables, and the cell voltage $V_{\mathrm{c}}$ and current $I_{\mathrm{c}}$ are chosen as system outputs, the fuel cell system model can be expressed as

$V_{\mathrm{c}}=G_{\mathrm{a} 2} V_{\mathrm{A}}+G_{\mathrm{S} 4} V_{\mathrm{S}}-R I_{\mathrm{c}}$,

$I_{\mathrm{c}}=G_{\mathrm{a} 1} V_{\mathrm{A}}+G_{\mathrm{S} 3} V_{\mathrm{S}}$,

where $G_{\mathrm{a} 1}=G_{\mathrm{a}} G_{1}, \quad G_{\mathrm{a} 2}=G_{\mathrm{a}} G_{2}, \quad G_{\mathrm{S} 3}=G_{\mathrm{S}} G_{3}, \quad G_{\mathrm{S} 4}=G_{\mathrm{S}} G_{4}$. Since $V_{\mathrm{c}}$ and $I_{\mathrm{c}}$ are dependent, (1) can be reduced to

$V_{\mathrm{c}}=\left(G_{\mathrm{a} 2}-R G_{\mathrm{a} 1}\right) V_{\mathrm{A}}+\left(G_{\mathrm{S} 4}-R G_{\mathrm{a} 1}\right) V_{\mathrm{S}}$

It is noticed that the cell voltage and cell current, since dependent, are not to be regulated concurrently with arbitrary set points. Either configuration (2) or (3), namely a multi-input single-output model, is employed as the basis of system identification, as well as an adjustable model for designing the fuel cell controller. 
Table 1

Operating conditions for system identification

\begin{tabular}{ll}
\hline Temperature $\left({ }^{\circ} \mathrm{C}\right)$ & 17 \\
Pressure $($ atm $)$ & 1 \\
Humidity $(\%)$ & 74 \\
Fuel cell temperature $\left({ }^{\circ} \mathrm{C}\right)$ & $35-40$ \\
Air pump voltage $(\mathrm{V})$ & $5 \pm 2$ \\
Anode reactant & $\mathrm{H}_{2}, 1.2 \mathrm{LPM}, 7 \mathrm{psig}$ \\
Cathode reactant & Natural air \\
Current density $\left(\mathrm{A} \mathrm{cm}{ }^{-2}\right)$ & 0.2 \\
Sampling frequency $(\mathrm{Hz})$ & 100 \\
\hline
\end{tabular}

\subsection{Off-line system identification}

The purpose of off-line system identification is to obtain the transfer functions between system inputs and outputs in (1) and (2) at certain operating points. The information provided from transfer functions, such as system order, parameters, and time delay, must be used for the adaptive controller design. Although many approaches are available, non-parametric system identification is one of the most effective to investigate the frequency response of the fuel cell stack.

The identification of the transfer function $G_{\mathrm{a} 1}=I_{\mathrm{c}} / V_{\mathrm{A}}$ is demonstrated between the cell current and air pump voltage under certain operating conditions, as described in Table 1. The hydrogen is supplied with a nominal rate of $1.2 \mathrm{LPM}$ at $7 \mathrm{psig}$ by a solenoid valve, which is always on during the process, but the output valve opens to purge chemical product for $2 \mathrm{~s}$ every $2 \mathrm{~min}$. Even though the purge valve is closed, the hydrogen is continually supplied and consumed to convert to electricity, while the water purging can be regarded as the external disturbance that helps excite system dynamics during identification. On the other hand, this disturbance can be easily controlled by the proposed adaptive controller.

The cell voltage is set fixed by an electronic load meter at $8.5 \mathrm{~V}$ for three or more identifications. The input voltage of the air pump is a sinusoidal function $V_{\mathrm{A}}=5+2 \cos (\omega t)$, whose frequency sweeps from 0.05 to $10 \mathrm{~Hz}$. Then, the dynamic signal analyzer (DSA) HP35670A takes $N$ samples of cell current $I_{\mathrm{c}}$ and calculates the magnitude and phase of frequency response $G_{\mathrm{a} 1}(\mathrm{j} \omega)$ as follows.

$\left|\hat{G}_{\mathrm{a} 1}(\mathrm{j} \omega)\right|=\sqrt{f_{\mathrm{s}}^{2}+f_{\mathrm{c}}^{2}}$,

$\hat{\phi}_{\mathrm{N}}(\mathrm{j} \omega)=\arg \hat{G}_{\mathrm{a} 1}(\mathrm{j} \omega)=-\arctan \left(\frac{f_{\mathrm{s}}}{f_{\mathrm{c}}}\right)$,

where

$f_{\mathrm{s}}=\frac{1}{N} \sum_{t=1}^{N} I_{\mathrm{c}}(t) \sin (\omega t)$ and $f_{\mathrm{c}}=\frac{1}{N} \sum_{t=1}^{N} I_{\mathrm{c}}(t) \cos (\omega t)$.

The corresponding frequency responses of $G_{\mathrm{a} 1}$ are shown in Fig. 4, where three test results do not have significant differences over the frequency range, and the resulting estimation of transfer function is then expressed in different orders as
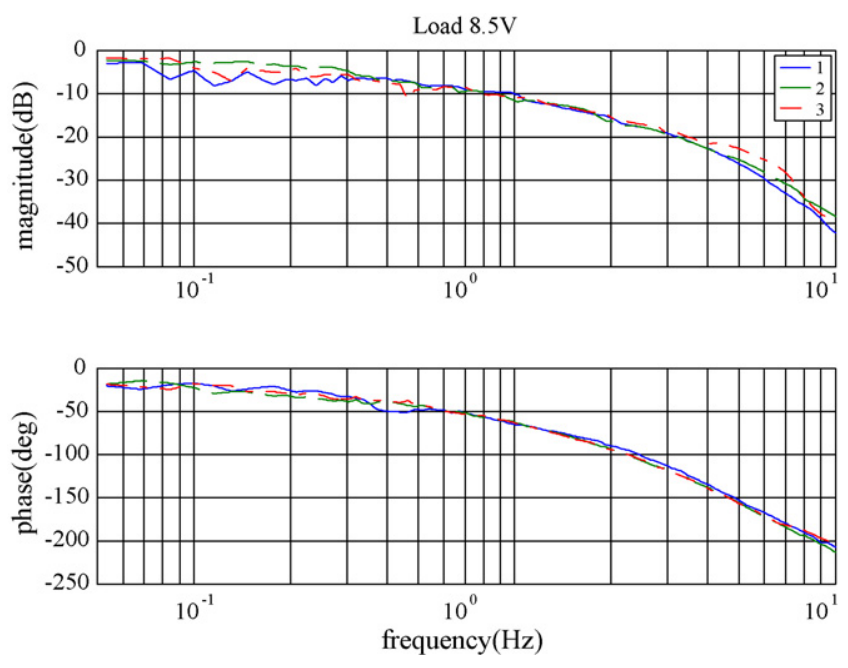

Fig. 4. Identified frequency responses of $G_{\mathrm{a} 1}$ at a load of $8.5 \mathrm{~V}$ for three tests.

First-order approximation:

$G_{\mathrm{a} 1}(s)=\frac{I_{\mathrm{c}}(s)}{V_{\mathrm{A}}(s)}=\frac{0.01444 s+0.08766}{s+0.229}$.

Second order approximation:

$G_{\mathrm{a} 1}(s)=\frac{0.0004543 s^{2}+0.1307 s+0.05606}{s^{2}+1.011 s+0.1392}$.

Third order approximation:

$G_{\mathrm{a} 1}(s)=\frac{0.002546 s^{3}+0.1356 s^{2}+0.06633 s+0.02382}{s^{3}+1.058 s^{2}+0.4321 s+0.06131}$.

Similar results can be also obtained for the transfer functions $G_{\mathrm{a} 2}, G_{\mathrm{S} 3}$, and $G_{\mathrm{S} 4}$, and bring the conclusion that a second-order transfer function may be sufficient to describe the dominant dynamics of a PEM fuel cell stack $[18,19]$. To facilitate the following adaptive controller design, a set of second-order continuous-time transfer functions and their discrete-time approximations of $0.01 \mathrm{~s}$ sampling time at a certain operating point are illustrated in Table 2.

Table 2

Illustration of identified second-order transfer function pairs in $s$ and $z$ domains

\begin{tabular}{|c|c|}
\hline$G_{\mathrm{a} 1}=I_{\mathrm{c}} / V_{\mathrm{A}}, V_{\mathrm{c}}=8 \mathrm{~V}$ & $G_{\mathrm{a} 2}=V_{\mathrm{c}} / V_{\mathrm{A}}, I_{\mathrm{c}}=3 \mathrm{~A}$ \\
\hline $0.9909 s+15.89$ & $0.3269 s+2.016$ \\
\hline$\overline{s^{2}+6.401 s+9.732}$ & $\overline{s^{2}+3.921 s+2.058}$ \\
\hline $0.01037 z-0.008835$ & $0.003305 z-0.003107$ \\
\hline$\overline{z^{2}-1.937 z+0.938}$ & $\overline{z^{2}-1.961 z+0.9616}$ \\
\hline$G_{\mathrm{S} 3}=I_{\mathrm{c}} / V_{\mathrm{S}}, V_{\mathrm{c}}=8 \mathrm{~V}$ & $G_{\mathrm{S} 4}=V_{\mathrm{c}} / V_{\mathrm{S}}, I_{\mathrm{c}}=3 \mathrm{~A}$ \\
\hline $0.2477 s+3.973$ & $0.08173 s+0.5041$ \\
\hline$\overline{s^{2}+6.401 s+9.732}$ & $\overline{s^{2}+3.921 s+2.058}$ \\
\hline $0.002594 z-0.002209$ & $0.0008263 z-0.0007769$ \\
\hline$\overline{z^{2}-1.937 z+0.938}$ & $z^{2}-1.961 z+0.9616$ \\
\hline
\end{tabular}




\section{Theory and calculation}

\subsection{On-line parameter estimation and adaptive control}

PEM fuel cells have a number of attributes to make them promising candidates for use in domestic appliances and transportation applications [25]. The power demand of automobiles depends on the driving conditions, and the provision of electricity from a fuel cell varies due to its system states, such as reactant flow rates, cell temperature, humidity, and pressure. The relationship between fuel cell output voltage and current is usually described by polarization curves, which also vary with cell temperature, pressure, humidity, and some other states. These time-varying and state-dependent properties are hardly depicted by simple mathematical models, but the system identification proves that it is possible to approximate fuel cell dynamics by transfer functions at a certain operating point. These transfer functions can be transformed to discrete-time parameter estimation models in the adaptive control loop of a fuel cell system subject to external disturbances as well as system parameter changes.

In practice, the fuel cell current can be regarded as an external disturbance to the system, which is requested by the demand for power by external loads. Therefore, the approximated block diagram of a fuel cell in Fig. 3 can further simplified as a twoinput and one-output structure.

\subsection{ARMA model and on-line parameter estimation}

As mentioned above, cell voltage and cell current are dependent, and thus are not to be regulated concurrently with arbitrary set points. Either (2) or (3) is used for on-line parameter estimation, and is usually represented as a discrete-time equation of difference operator, leading to the following auto-regressive moving-average (ARMA) model [26]:

$A(q, k) y(k)=B(q, k) u(k)+w(k)$,

$A(q, k)=a_{0}(k)+a_{1}(k) q^{-1}+\cdots+a_{r}(k) q^{-r}$,

$B(q, k)=B_{1}(k) q^{-1}+B_{2}(k) q^{-2}+\cdots+B_{r}(k) q^{-r}$,

where $y=I_{\mathrm{c}}$ or $V_{\mathrm{c}}$ denotes the output variable, $u=\left[\begin{array}{ll}u_{1} & u_{2}\end{array}\right]^{\mathrm{T}}=\left[V_{\mathrm{A}}\right.$ $\left.V_{\mathrm{S}}\right]^{\mathrm{T}}$ represents the 2-tuple input vector, $w$ is composed of higher-order dynamics and disturbances, and is known as an estimation error vector. The coefficients $a_{i}$ 's are scalars while $B_{i}$ 's are 2-tuple row vectors for $i=1,2, \ldots, r$, the integer $k$ denotes the time instant of sampling, and $r$ is the system order. Without loss of generality, $a_{0}=1$. In a succinct form, the term $A(q, k) y(k)$ is the auto-regression part, where $q^{-1}$ is a backward shift operator, and $q^{-h} y(k)$ represents the past output $y(k-h)$; $h=1,2, \ldots r ; B(q, k) u(k)$ denotes the moving average of past inputs, where $q^{-h} u(k)=u(k-h)$.

The approach of the recursive least square algorithm for system identification is to predict the system output according to the past information of input and output measurements, as well as the updated set of system parameters. From (10) to (12), the estimation of $y(k)$ is expressed as

$\hat{y}(k)=\phi^{\mathrm{T}}(k-1) \hat{\theta}(k-1)$,

where $\phi^{\mathrm{T}}(k-1)=\left[\begin{array}{lllll}-y(k-1) & \ldots & -y(k-r) & u_{1}(k-1) & \ldots\end{array}\right.$ $\left.u_{1}(k-r) u_{2}(k-1) \ldots u_{2}(k-r)\right]$ and $\hat{\theta}(k-1)$ is the estimated parameter vector of $\hat{a}_{i}^{\prime} \mathrm{s}$ and $\hat{B}_{i}^{\prime} \mathrm{s}$. The estimation error $w(k)$ is defined as $y(k)-\hat{y}(k)$.

At step $k$, when the new output is measured, the updated set of parameters are calculated by [26]

$$
\begin{aligned}
& \hat{\theta}(k)=\hat{\theta}(k-1)+K(k)\left[y(k)-\phi^{\mathrm{T}}(k-1) \hat{\theta}(k-1)\right], \\
& K(k)=P(k-1) \phi(k-1)\left[\lambda+\phi^{\mathrm{T}}(k-1) P(k-1) \phi(k-1)\right]^{-1},
\end{aligned}
$$

$P(k)=\frac{\left[I-K(k) \phi^{\mathrm{T}}(k-1)\right] P(k-1)}{\lambda}$,

where the estimation gain $K(k)$ brings the relative information of new measurements to update the parameter estimation, and the covariance matrix $P(k)$ characterizes the difference between the estimated parameters and their true values. Initially, $P(0)$ is chosen as a large positive number, for example $10^{3} I$, where $I$ is an identity matrix, to render the inaccurate initial guess $\hat{\theta}(0)$ quickly negligible. The coefficient $0<\lambda<1$ is called the forgetting factor, which places more importance on the new information for updating system parameters, and less attention on the past information.

\subsection{Model reference adaptive control (MRAC)}

Model reference adaptive control is one of the promising strategies for a complex fuel cell system. No matter how complicated the system is, its desired output can be designated to follow the output of a reference model with specified dynamics. The model reference adaptive control strategy includes the specification of a reference model with the desired dynamics, on-line parameter estimation, and calculation of control gains. This adaptive control scenario is illustrated in Fig. 5.

From the previous result of system identification, the approximated blocks of the fuel cell system of interest can be well described as second-order subsystems. Without loss of gener-

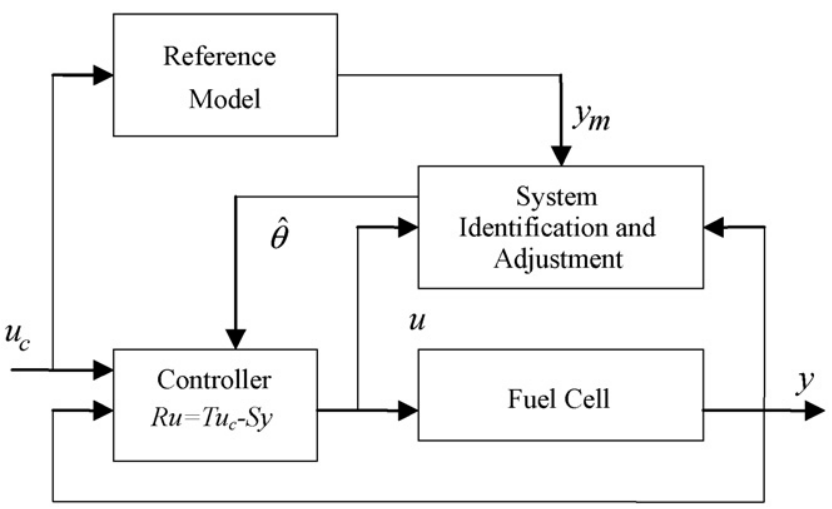

Fig. 5. Model reference adaptive control scenario of fuel cell. 
ality, the following control law is derived for an SISO system whose model is identified on-line and is denoted by

$\hat{A}(q) y(k)=\hat{B}(q) u(k)$,

where $\hat{A}(q)=q^{2}+\hat{a}_{1} q+\hat{a}_{2}$, and $\hat{B}(q)=\hat{b}_{1} q+\hat{b}_{2}$. For a standard feedback control law

$R(q) u(k)=T(q) u_{\mathrm{c}}(k)+S(q) y(k)$,

where $u_{\mathrm{c}}$ is a reference signal. The closed-loop relationship between $u_{\mathrm{c}}(k)$ and $y(k)$ can be written as

$y(k)=\frac{\hat{B} T}{\hat{A} R+\hat{B} S} u_{\mathrm{c}}(k)$,

in which the index $q$ is omitted for simplicity. The desired closedloop model is chosen as

$A_{\mathrm{m}} y_{\mathrm{m}}(k)=B_{\mathrm{m}} u_{\mathrm{c}}(k)$,

where $A_{\mathrm{m}}(q)=q^{2}+a_{\mathrm{m} 1} q+a_{\mathrm{m} 2}$ and $B_{\mathrm{m}}(q)=b_{\mathrm{m} 1} q+b_{\mathrm{m} 2}$, then a perfect model-following condition becomes

$\frac{\hat{B} T}{\hat{A} R+\hat{B} S}=\frac{B_{\mathrm{m}}}{A_{\mathrm{m}}}$.

Under the conditions of compatibility and causality, the control polynomials $T$ and $S$ are obtained by the Bezout or Diophantine equation:

$\hat{A} R+\hat{B} S=A_{\mathrm{m}} A_{\mathrm{o}}$,

where $R(q)=q+r_{1}, S(q)=s_{0} q+s_{1}$, and $A_{0}(q)=q+a_{0}$ is known as an observer polynomial, which is always cancelled in the transfer function between the output and reference signal. When the unit steady-state gain of $B_{\mathrm{m}} / A_{\mathrm{m}}$ is designed and $B_{\mathrm{m}}=\beta \hat{B}$ is selected, the control polynomial $T$ becomes simply $\beta A_{\mathrm{o}}$. In summary, the parameters of those control polynomials are calculated after system parameters $\hat{a}_{1}, \hat{a}_{2}, \hat{b}_{1}$, and $\hat{b}_{2}$ are estimated:

$r_{1}=\frac{a_{\mathrm{o}} a_{\mathrm{m} 2} \hat{b}_{1}^{2}+\left(\hat{a}_{2}-a_{\mathrm{m} 2}-a_{\mathrm{o}} a_{\mathrm{m} 1}\right) \hat{b}_{1} \hat{b}_{2}+\left(a_{\mathrm{o}}+a_{\mathrm{m} 1}-\hat{a}_{1}\right) \hat{b}_{2}^{2}}{\alpha}$

$s_{0}=\frac{\hat{b}_{2}\left(a_{\mathrm{o}} a_{\mathrm{m} 1}-\hat{a}_{2}-a_{\mathrm{m} 1} \hat{a}_{1}+a_{\mathrm{m} 2}-\hat{a}_{1} a_{\mathrm{o}}\right)+\hat{b}_{1}\left(a_{\mathrm{m} 1} \hat{a}_{2}-\hat{a}_{1} \hat{a}_{2}-a_{\mathrm{o}} a_{\mathrm{m} 2}-a_{\mathrm{o}} \hat{a}_{2}\right)}{\alpha}$.

$s_{1}=\frac{\hat{b}_{2}\left(\hat{a}_{1} \hat{a}_{2}-a_{\mathrm{m} 1} \hat{a}_{2}+a_{\mathrm{o}} a_{\mathrm{m} 2}-\hat{a}_{2} a_{\mathrm{o}}\right)+\hat{b}_{1}\left(a_{\mathrm{m} 2} \hat{a}_{2}-\hat{a}_{2}^{2}-a_{\mathrm{o}} a_{\mathrm{m} 2} \hat{a}_{1}-a_{\mathrm{o}} \hat{a}_{2} a_{\mathrm{m} 1}\right)}{\alpha}$.

$\alpha=\hat{b}_{2}^{2}-\hat{a}_{1} \hat{b}_{1} \hat{b}_{2}+\hat{a}_{2} \hat{b}_{1}^{2}$.

$\beta=\frac{b_{\mathrm{m} 1}+b_{\mathrm{m} 2}}{\hat{b}_{1}+\hat{b}_{2}}$.

In the following experiments, $a_{\mathrm{m} 1}=0, a_{\mathrm{m} 2}=0.01$, and $a_{\mathrm{o}}=-0.1$, which correspond to the desired closed-loop poles assigned at -0.1 and $\pm 0.1 j$ within the unit circle of $z$-plane. The above algorithm for MRAC can be extended to the case of two inputs, air and hydrogen flow rates, and one output, cell voltage, as shown in Fig. 6 . The parameter $\kappa$ is defined as the nominal ratio between the average voltages of solenoid valve

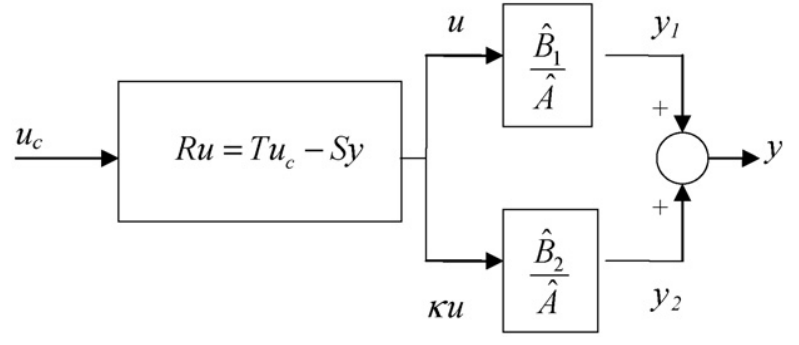

Fig. 6. Multivariable adaptive control block diagram

and air pump, which accounts for the nominal ratio between the flow rates of hydrogen and oxygen. The determination of control functions $R, T$, and $S$ still applies through (23)-(27) by simply replacing $\hat{B}(q)$ by $\hat{B}_{1}(q)+\kappa \hat{B}_{2}(q)$.

\section{Result and discussion}

From the perspective of the certainty equivalence principle in the system identification and adaptive control theories, a linear model of reduced order with time-varying parameters is usually used to generate the control law as if it were a true system no matter whether it is linear or nonlinear [26]. Five adaptive control scenarios are investigated: the regulation of cell voltage by the flow rate of air or hydrogen, the regulation of cell current by the flow rate of air or hydrogen, and the regulation of cell voltage by the flow rates of air and hydrogen. These scenarios provide a systematic way of demonstrating the effectiveness of the proposed controller for various situations of a change in the external load with which the change of internal impedance and the corresponding states accompany. The first four scenarios are SISO cases, while the last one pertains to the multivariable configuration.

The experimental setup of the fuel cell stack and its peripheral devices is shown in Fig. 7. On-line parameter estimation and model reference adaptive control law are performed on a laptop computer using Matlab. The fuel cell power is dissipated on an electronic load meter by which either cell current or cell voltage remains constant while the other is regulated. Their dependence, however, is characterized by polarization curves as functions of pressure, humidity, and temperature. The air-flow rate is controlled by an air pump, whose property is specified by experiments with the relationship of flow rate and driving voltage, as shown in Fig. 8. The hydrogen flow rate is kept constant at $1.2 \mathrm{LPM}$ at $7 \mathrm{psig}$ in the SISO cases, but is adaptively controlled by the solenoid valve at on-off sequences. Both the air and hydrogen are not humidified, and the cell temperature is monitored and sequentially controlled around $35-40^{\circ} \mathrm{C}$. 


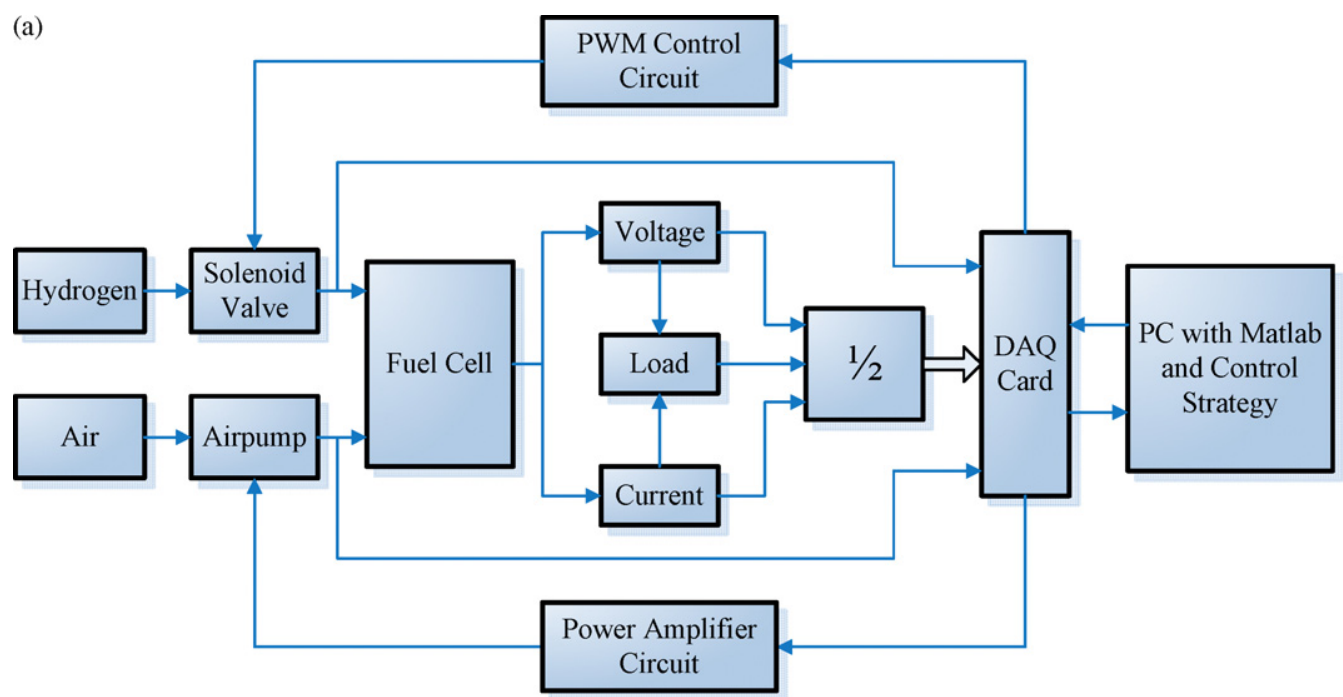

(b)

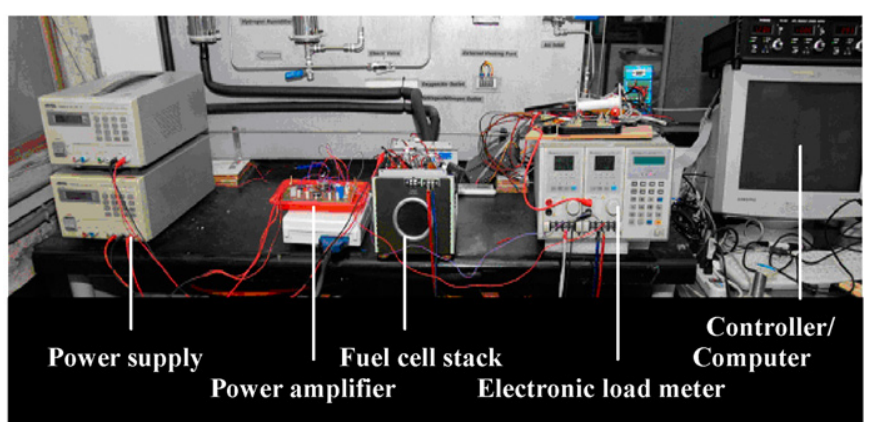

Fig. 7. (a) Fuel cell control block diagram and (b) experimental setup.

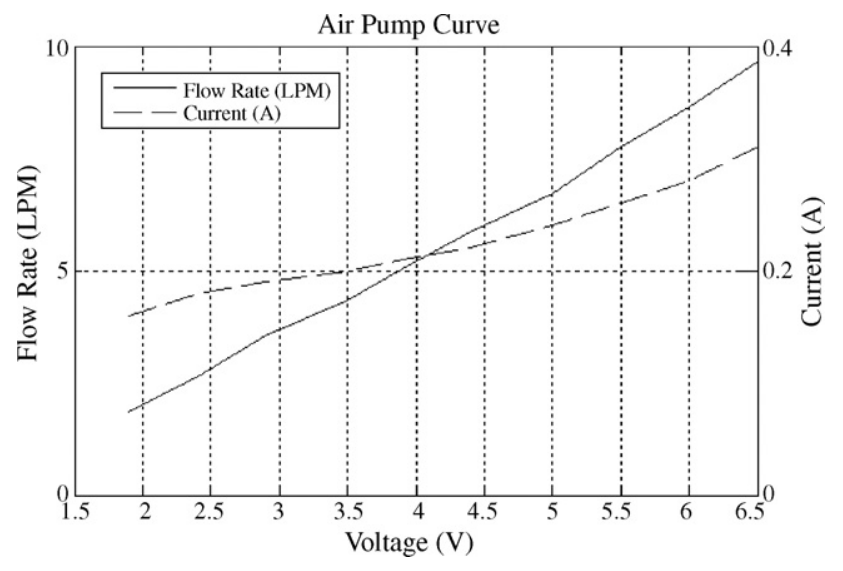

Fig. 8. Air-flow rate vs. air pump voltage.
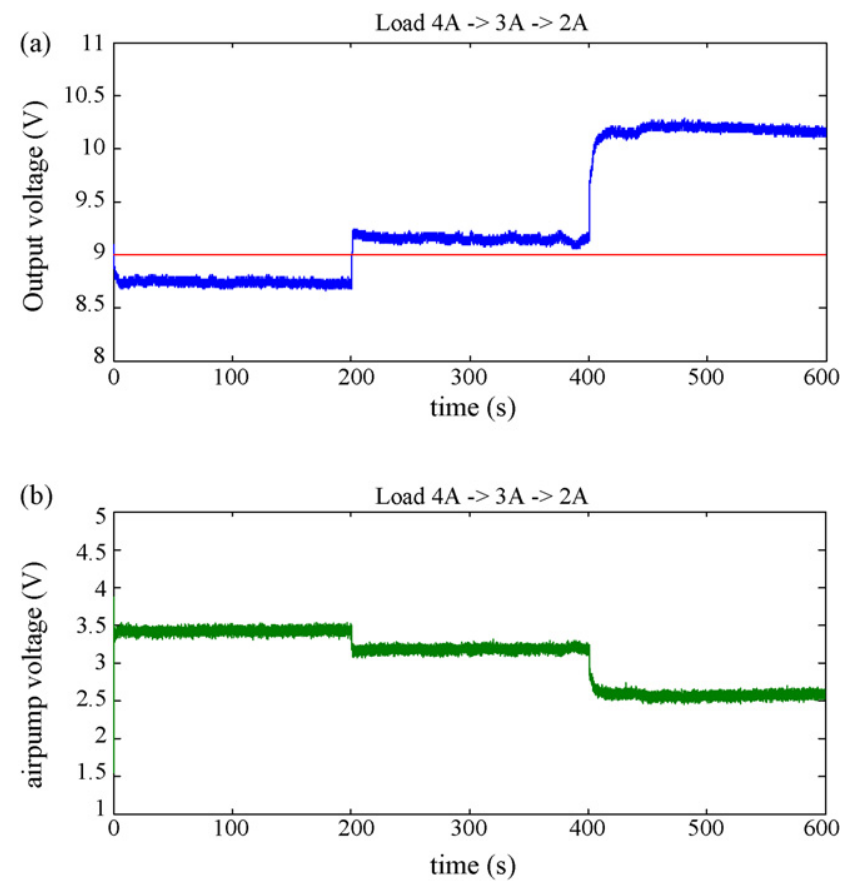

Fig. 9. Cell voltage control with fixed system parameters. 
(a)
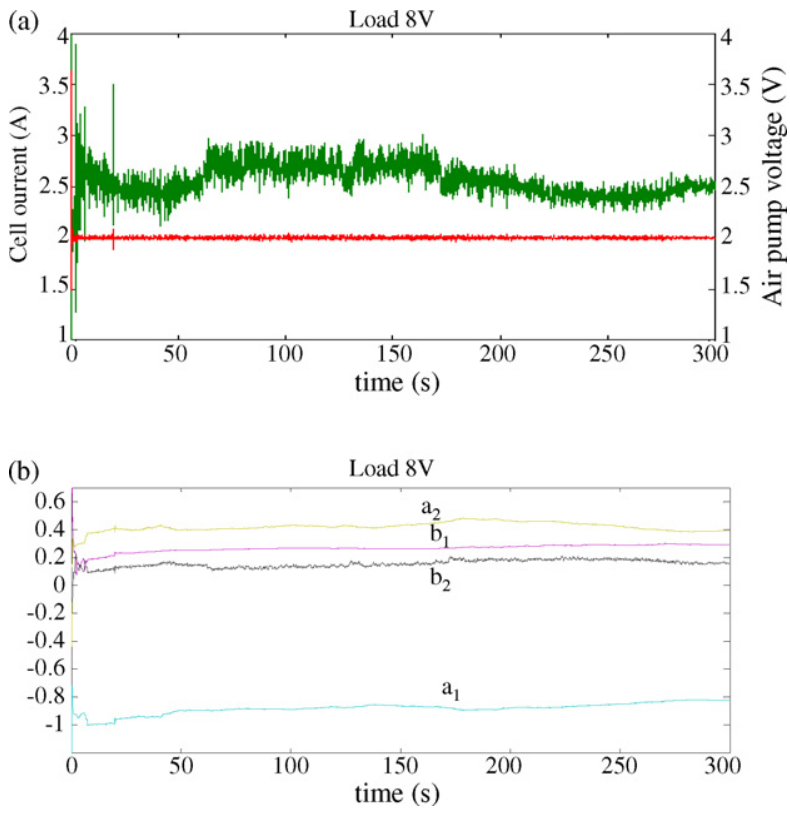

Fig. 10. (a) Adaptive control of cell current (2 A) by the air pump voltage (upper curve) under the cell voltage set at $8 \mathrm{~V}$, and (b) the corresponding parameter estimation.
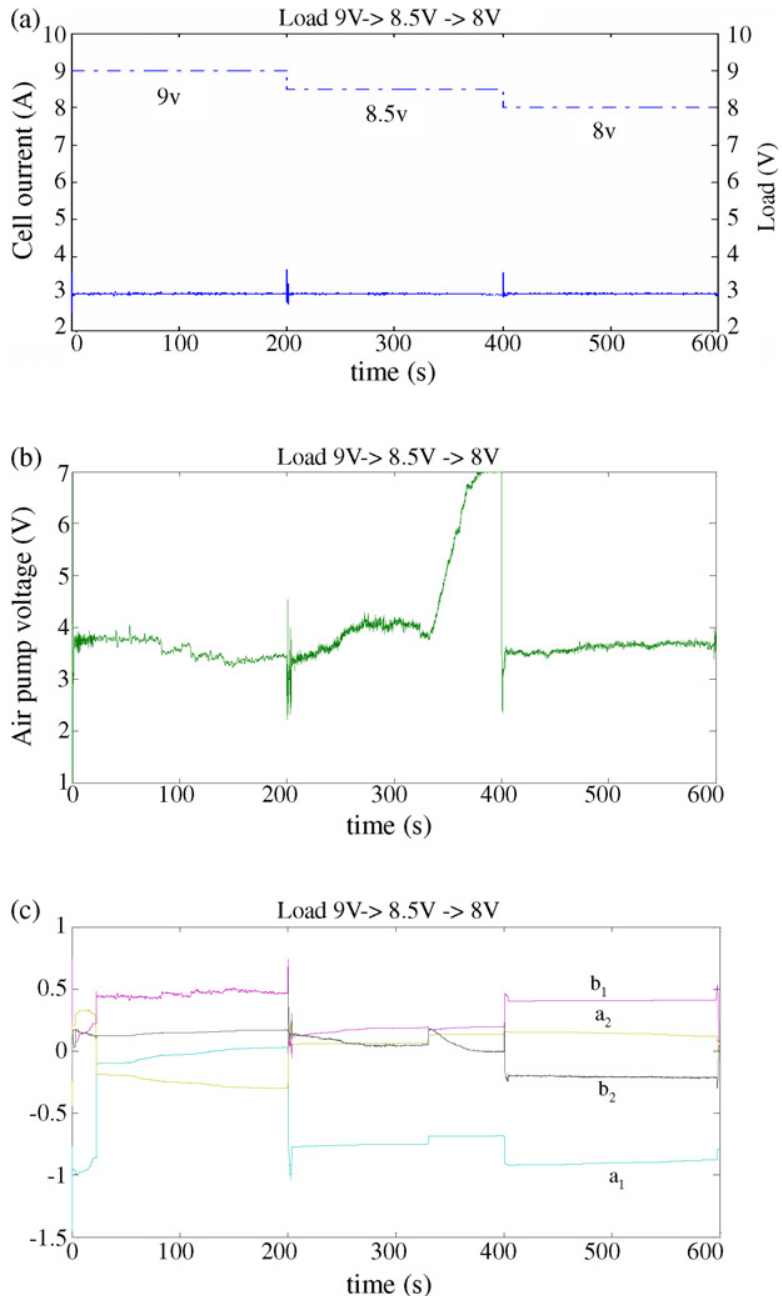

Fig. 11. (a) Adaptive control of cell current (solid curve) at $3 \mathrm{~A}$ for the cell voltage (dashed line) of $9 \mathrm{~V}, 8.5 \mathrm{~V}$, and $8 \mathrm{~V}$, (b) the input air pump voltage, and (c) the corresponding parameter estimation
It is noteworthy that the fuel cell has a built-in water and thermal management subsystem; thus, all the following experiments focus on the justification and effectiveness of the proposed adaptive control strategy. In addition, the fuel cell used in this research was not in its best condition due to the damage and aging of membranes, so that the fuel stack could only operate in a relatively conservative range of voltage, current, and power.

\subsection{Control of cell voltage with fixed parameters}

Before the adaptive control performance is investigated, it is interesting to observe the performance of cell voltage that is adjusted by air pump voltage according to the control law with fixed control parameters in (23)-(27). These parameters are determined by a fixed set of system parameters $a_{1}=-1.1059$, $b_{1}=8.7898, a_{2}=0.3567$, and $b_{2}=0.2405$, while the hydrogen is supplied at a constant flow rate of $1.2 \mathrm{LPM}$ at $7 \mathrm{psig}$. As shown in
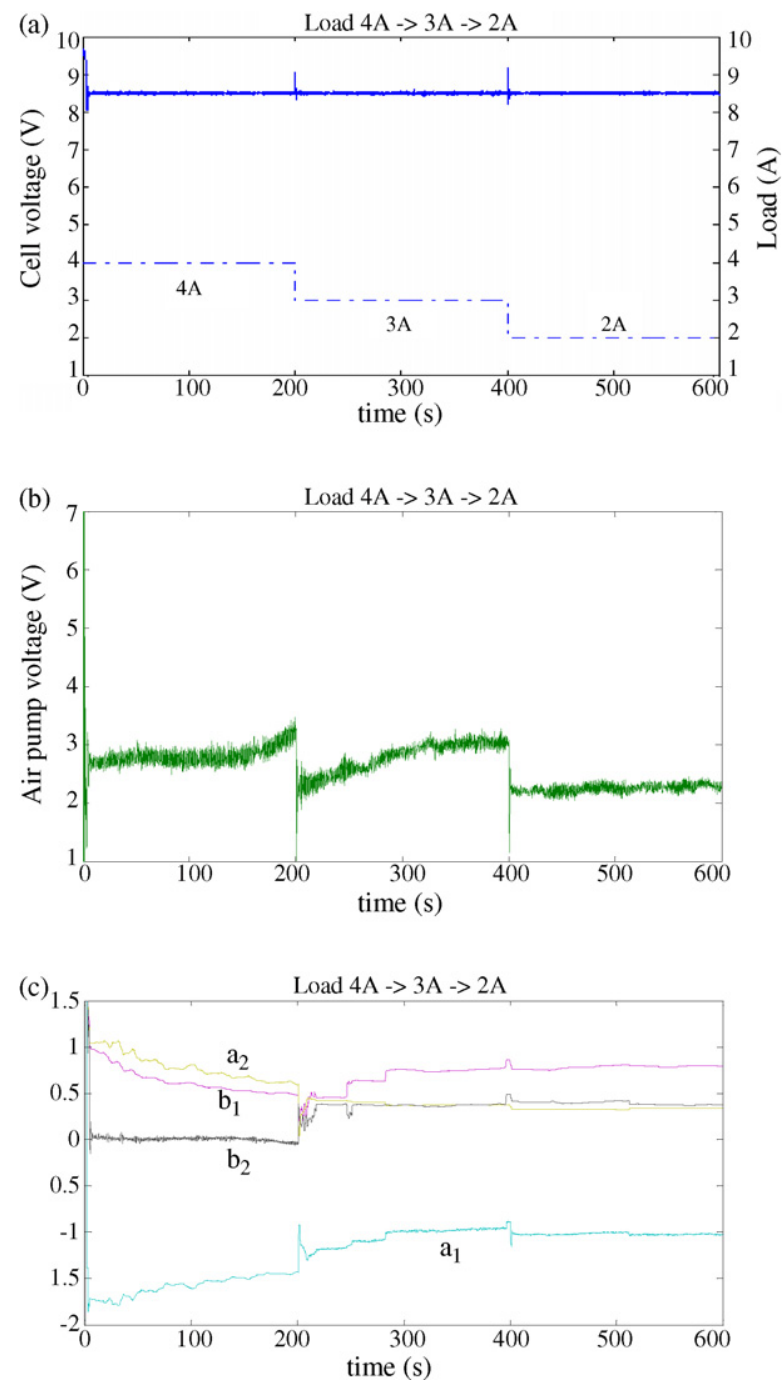

Fig. 12. (a) Adaptive control of cell voltage (solid curve) at $8.5 \mathrm{~V}$ under the load demand (dashed line) of $4 \mathrm{~A}, 3 \mathrm{~A}$, and $2 \mathrm{~A}$, (b) the corresponding air pump voltage, and (c) parameter estimation. 
Fig. 9, the cell voltage does not approach the desired command of $9 \mathrm{~V}$ subject to the variation of the current load from $4 \mathrm{~A}$ and $3 \mathrm{~A}$ to $2 \mathrm{~A}$ for $200 \mathrm{~s}$ each. It is concluded that the conventional control strategy derived from fixed system parameters seems to lack robustness to external disturbances as well as to the variation of system parameters, and the large variation in cell voltage will cause the DC/DC converter to regulate the output voltage with lower efficiency.

\subsection{Regulation of cell current by air-flow rate}

First, adaptive control of the fuel cell current by the air pump voltage corresponding to the air pump flow rate is demonstrated. When the output voltage is fixed by the load meter and the hydrogen flow is kept steady by the solenoid valve, the cell current is adaptively adjusted by the air pump voltage on the demand for power consumption subject to the plant variation. This SISO process is simply described by the transfer function $G_{\mathrm{a} 1}$ which is transformed into a discrete-time model and is easily expressed as an ARMA model with time-varying parameters.

For a 2 A current demand, the load voltage is set at $8 \mathrm{~V}$, and the hydrogen is supplied continuously with $1.2 \mathrm{LPM}$ at $7 \mathrm{psig}$. Notice that hydrogen is oversupplied under this situation. The time responses of the air pump voltage input and cell current output are shown in Fig. 10(a), while the corresponding variation of parameters estimated on-line is depicted in Fig. 10(b). It is found that the system parameters did not vary much, and the cell current was easily regulated within $2 \pm 0.02 \mathrm{~A}$ rms by adjusting the air-flow rate. When the cell voltage shifts from $9 \mathrm{~V}$ through $8.5 \mathrm{~V}$ to $8 \mathrm{~V}$, at 200 and $400 \mathrm{~s}$, the current is regulated at $3 \mathrm{~A}$, as shown in Fig. 11(a), by adaptively adjusting the air pump voltage to change the air-flow rate in Fig. 11(b). The corresponding parameter estimation is displayed in Fig. 11(c). Various settings of cell voltage mean different operating points, which result in different parameters in the second-order transfer function. At the junctions of voltage change, the cell current experienced abrupt increase, but was immediately adapted to its desired value within $\pm 0.02 \mathrm{~A}$ rms. This experiment shows that the proposed adaptive control is robust to the plant variation and power demand.

\subsection{Regulation of cell voltage by air-flow rate}

In many applications, the power source has to be kept at a constant voltage, while the current is drawn based on the demand of the load. This happens quite often for fuel cells used on electric vehicles. If hydrogen is constantly oversupplied with 1.2 LPM at $7 \mathrm{psig}$, and the cell current is drawn from $4 \mathrm{~A}$ through $3 \mathrm{~A}$ to $2 \mathrm{~A}$, the voltage will be well regulated at $8.5 \mathrm{~V}$ by the air-flow rate, as shown in Fig. 12(a). The corresponding time history of air pump voltage is presented in Fig. 12(b). It is not surprising that the system parameters in Fig. 12(c) vary but are soon identified at different operating points, while the control law is adaptively changed to keep the cell voltage within a variation of $\pm 0.1 \mathrm{~V}$ of the desired value.
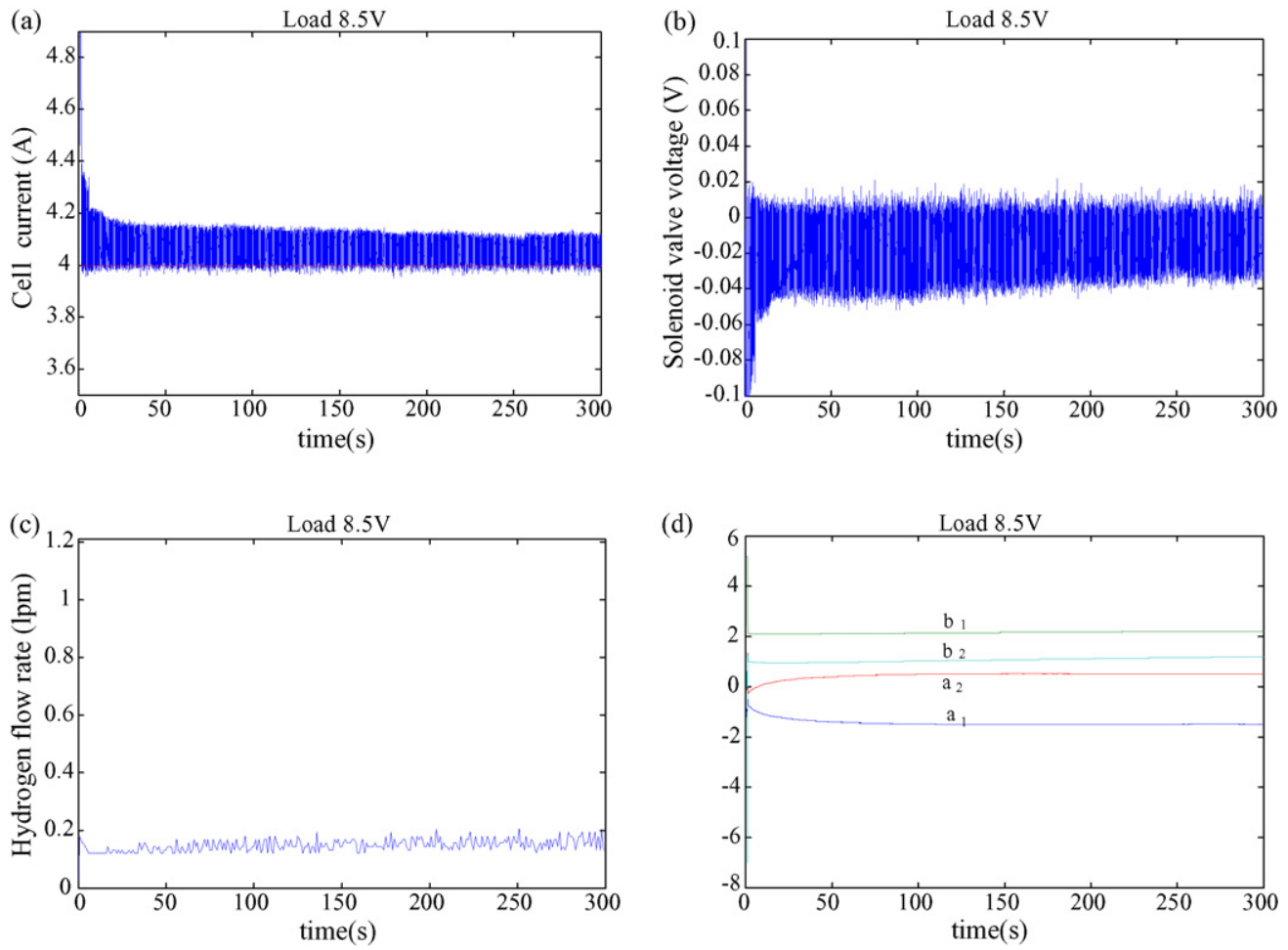

(d)

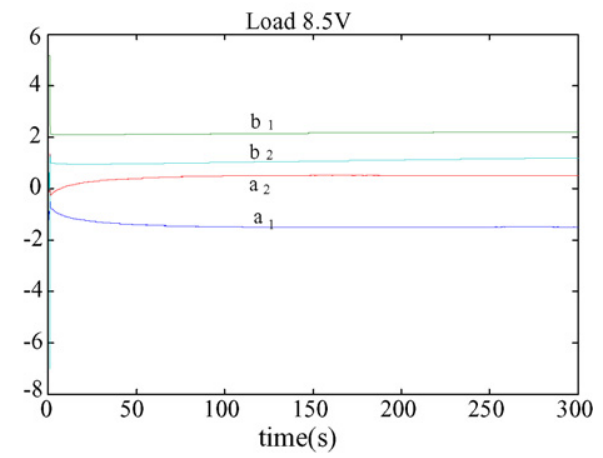

Fig. 13. (a) Adaptive control of cell current by (b) the voltage signal to the solenoid valve with (c) its corresponding hydrogen flow rate, while (d) system parameters are estimated. 


\subsection{Regulation of cell current by hydrogen flow rate}

It is also interesting to investigate how well the cell current is controlled by the hydrogen flow. When the air pump voltage is set at $5 \mathrm{~V}$ with about 6.6-6.8 LPM air-flow, the cell voltage is fixed at $8.5 \mathrm{~V}$, and the desired current is $4 \mathrm{~A}$, the output current approaches $4.08 \mathrm{~A}$ with a minor error of $2 \%$, as shown in Fig. 13(a). Although the cell current presents minor oscillation of $\pm 0.08 \mathrm{~A}$, the hydrogen flow rate is measured about $0.123 \mathrm{LPM}$, which is only about $10 \%$ consumption compared to the excessive usage of hydrogen at 1.2 LPM. During the adaptive control process, a PWM circuit is designed to control the solenoid valve at $100 \mathrm{~Hz}$. The voltage signal controlling the on-off actuation of solenoid valve is shown in Fig. 13(b), and is used to calculate the average hydrogen flow rate over each second, as shown in Fig. 13(c). The corresponding on-line parameter estimates are displayed in Fig. 13(d) for the linearly approximated system model.

With the same setting of air pump voltage, the cell voltage is fixed at $8.5 \mathrm{~V}$ for the first $200 \mathrm{~s}, 9 \mathrm{~V}$ for the next $200 \mathrm{~s}$, and $9.5 \mathrm{~V}$ for the last $200 \mathrm{~s}$, while the desired cell current is specified at 5 A, 4 A and 3 A. As shown in Fig. 14(a), the cell current is controlled successfully by adjusting the flow rate of hydrogen with a solenoid valve as depicted in Fig. 14(b), and the corresponding parameter estimation is illustrated in Fig. 14(c). As expected, $77.3 \%$ of hydrogen is saved during the first $200 \mathrm{~s}, 84 \%$ during the next $200 \mathrm{~s}$, and $85 \%$ for the last $200 \mathrm{~s}$, compared with the constant hydrogen flow of 1.2 LPM. It is also interesting to find that the steady-state error of current response is within $\pm 0.35 \%$ with minor oscillations.

\subsection{Regulation of cell voltage by hydrogen flow rate}

In this experiment, the air pump voltage is fixed at $5 \mathrm{~V}$ to which the corresponding flow rate is around 6.6-6.8 LPM, while the hydrogen pressure is kept at $7 \mathrm{psig}$. The operating state of the solenoid valve is either fully on at $12 \mathrm{~V}$ or fully off at $0 \mathrm{~V}$. The flow rate of hydrogen can be controlled by adjusting the duty cycle, or the open period of the valve, which is determined adaptively by the control law and a carrier signal to chop into a pulse width modulation (PWM) signal. Fig. 15(a) shows the controlled cell voltages from $9.5 \mathrm{~V}$ through $9 \mathrm{~V}$ to $8.5 \mathrm{~V}$ on the demand of a $3 \mathrm{~A}$ load, controlled by the hydrogen flow rate in Fig. 15(b), and the corresponding time-varying parameters are estimated in Fig. 15(c).

It is found that, at different power demands, the cell voltage controlled by the hydrogen flow presents larger steady-state error and larger amplitude of oscillation that are controlled by the air-flow. In the first $200 \mathrm{~s}$, the average voltage is $9.54 \mathrm{~V}$ with $0.43 \%$ error, and the oscillatory amplitude is within $\pm 0.125 \mathrm{~V}$; for the next $200 \mathrm{~s}$, the average voltage is $9.18 \mathrm{~V}$ with $2 \%$ error and $\pm 0.225 \mathrm{~V}$ oscillation; while the average voltage is $8.78 \mathrm{~V}$ with $3.26 \%$ error and $\pm 0.375 \mathrm{~V}$ oscillation for the last $200 \mathrm{~s}$. Higher oscillation of cell voltage occurs at a lower power output because of the pulsation and overcharge of hydrogen flow due to the on-off action of the solenoid valve. This can be improved by the use of a proportional solenoid valve whose opening can be finely
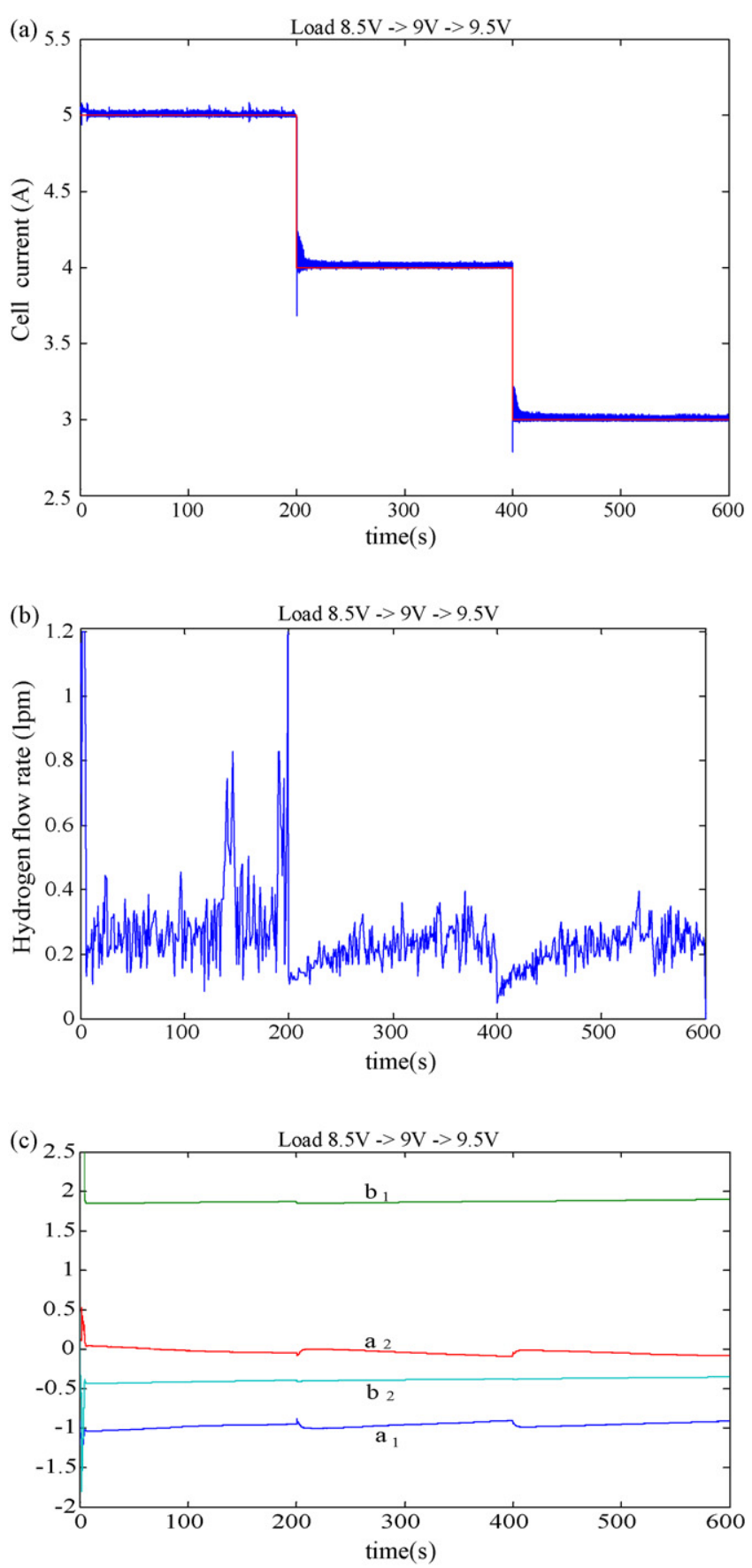

Fig. 14. (a) Adaptive control of cell current by (b) hydrogen flow rate while (c) system parameters are estimated.

adjusted. However, the amount of hydrogen consumed is much less than the continuous feeding of 1.2 LPM. From Fig. 15(b), the average flow rate of hydrogen is 0.17 LPM during the first $200 \mathrm{~s}$, and $86.2 \%$ hydrogen is saved; the average flow rate of hydrogen is 0.16 LPM during the next $200 \mathrm{~s}$ with a saving of $86.9 \%$; while $88.6 \%$ hydrogen is saved with the flow rate at 0.14 LPM during the last $200 \mathrm{~s}$.

In the case when the cell voltage is controlled at $9 \mathrm{~V}$ on various demands of load from $4 \mathrm{~A}$ through $3 \mathrm{~A}$ to $2 \mathrm{~A}$, as shown in Fig. 16(a), the response of the cell voltage also shows an oscillatory behavior, especially at lower power due to the reason 

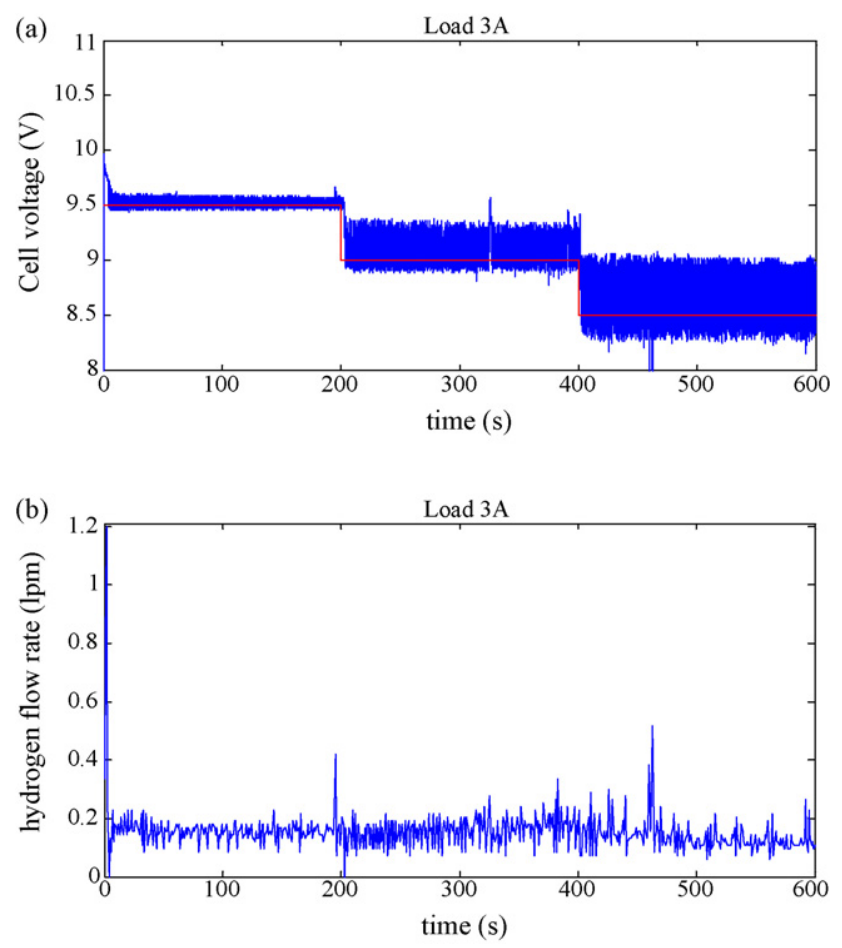

(c)

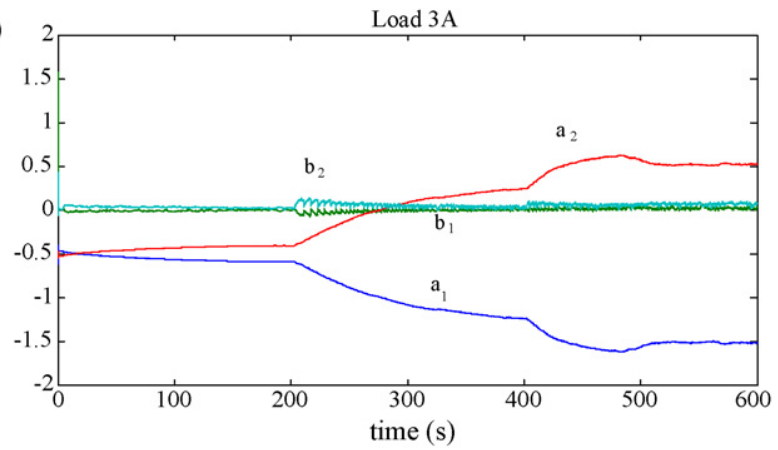

Fig. 15. (a) Adaptive control of cell voltage from $9.5 \mathrm{~V}$ through $9 \mathrm{~V}$ to $8.5 \mathrm{~V}$ at $3 \mathrm{~A}$ load, (b) the required flow rate of hydrogen, and (c) the corresponding parameter estimation.

mentioned in the previous case. The average voltage is $9.08 \mathrm{~V}$ with $0.92 \%$ error for the first $200 \mathrm{~s}$, and the average voltage is $9.11 \mathrm{~V}$ with $1.26 \%$ error for the next $200 \mathrm{~s}$, while the average voltage is $9.34 \mathrm{~V}$ with $3.74 \%$ error for the last $200 \mathrm{~s}$. The corresponding input of the hydrogen flow rate and the parameter variation are shown, respectively, in Fig. 16(b) and (c). The hydrogen consumption is saved for $84.8 \%$ for $4 \mathrm{~A}$ load, $90.3 \%$ for $3 \mathrm{~A}$ load, and $92.9 \%$ for $2 \mathrm{~A}$ load, in comparison with the constant flow rate of 1.2 LPM.

\subsection{Regulation of cell voltage both by air and hydrogen flow rates}

In the previous cases, the flow rate of either air or hydrogen is able to control the cell voltage and current adaptively based on the SISO model. Would the air pump and solenoid valve work together to regulate the cell voltage due to the demand of the load current? Theoretically, the stoichiometry
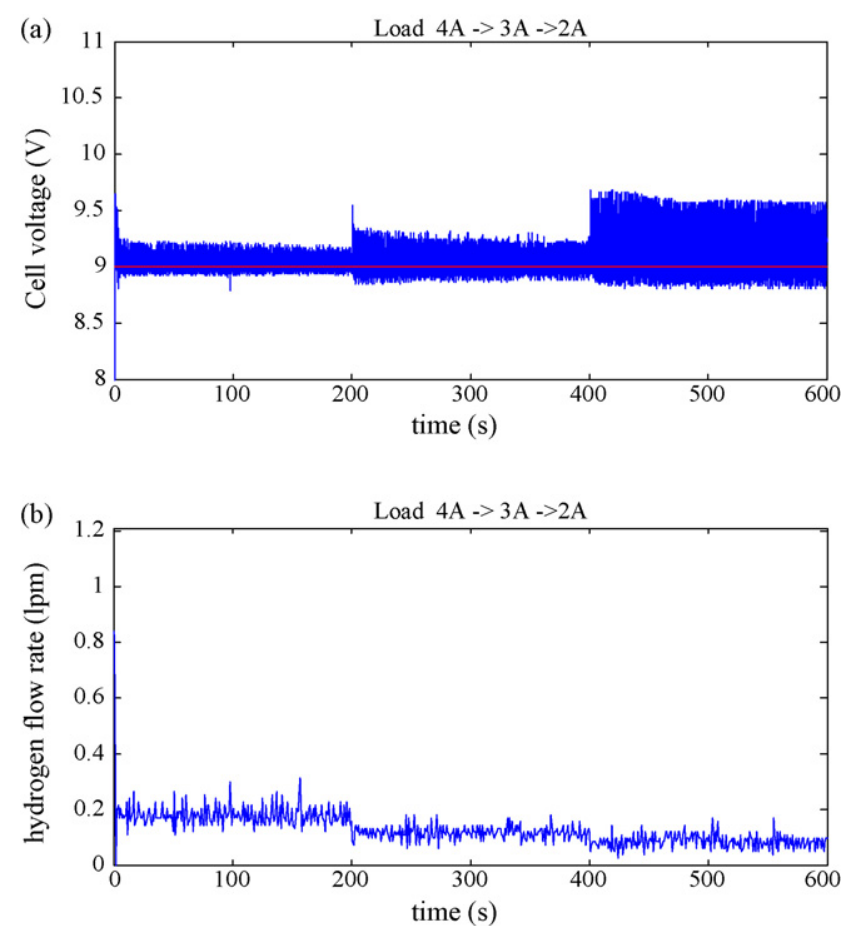

(c)

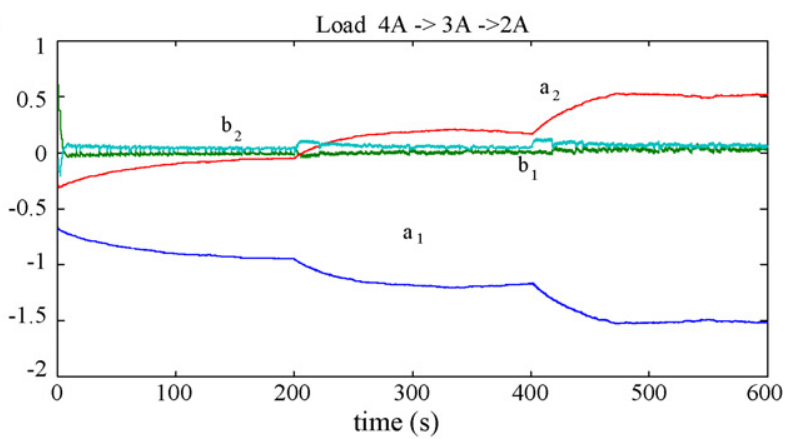

Fig. 16. Adaptive control of cell voltage at load from $4 \mathrm{~A}$ through $3 \mathrm{~A}$ to $2 \mathrm{~A}$, (b) the required flow rate of hydrogen, and (c) the corresponding parameter estimation.

of hydrogen and oxygen in the chemical reaction of PEM fuel cell is $2: 1$. If the cathode side is supplied with air, the stoichiometric ratio between hydrogen and air becomes approximately $2: 5$. In practice, an excessive amount of oxygen is requested for the fuel cell to operate stably [15]. From the above experiments, the parameter $\kappa$ that denotes the ratio between the average voltages of the solenoid valve and air pump was found at a nominal number of 0.04 as the fuel cell operates in a steady-state. This nominal number will be applied for the multivariable adaptive control described in Fig. 6 in the following experiments.

The pressure of hydrogen from the storage still maintains at 7 psig before entering the fuel cell through the solenoid valve. Both the air pump and solenoid valve supply oxygen and hydrogen with a proportional ratio of $\kappa$ to regulate the cell voltage at $9.5 \mathrm{~V}$ while the load current demand varies from $4 \mathrm{~A}$ through 3 A to $2 \mathrm{~A}$ at 200 and $400 \mathrm{~s}$, as shown in Fig. 17(a). The adaptive control law of voltages of the air pump and solenoid valve is shown in Fig. 17(b); the corresponding hydrogen flow rate is 

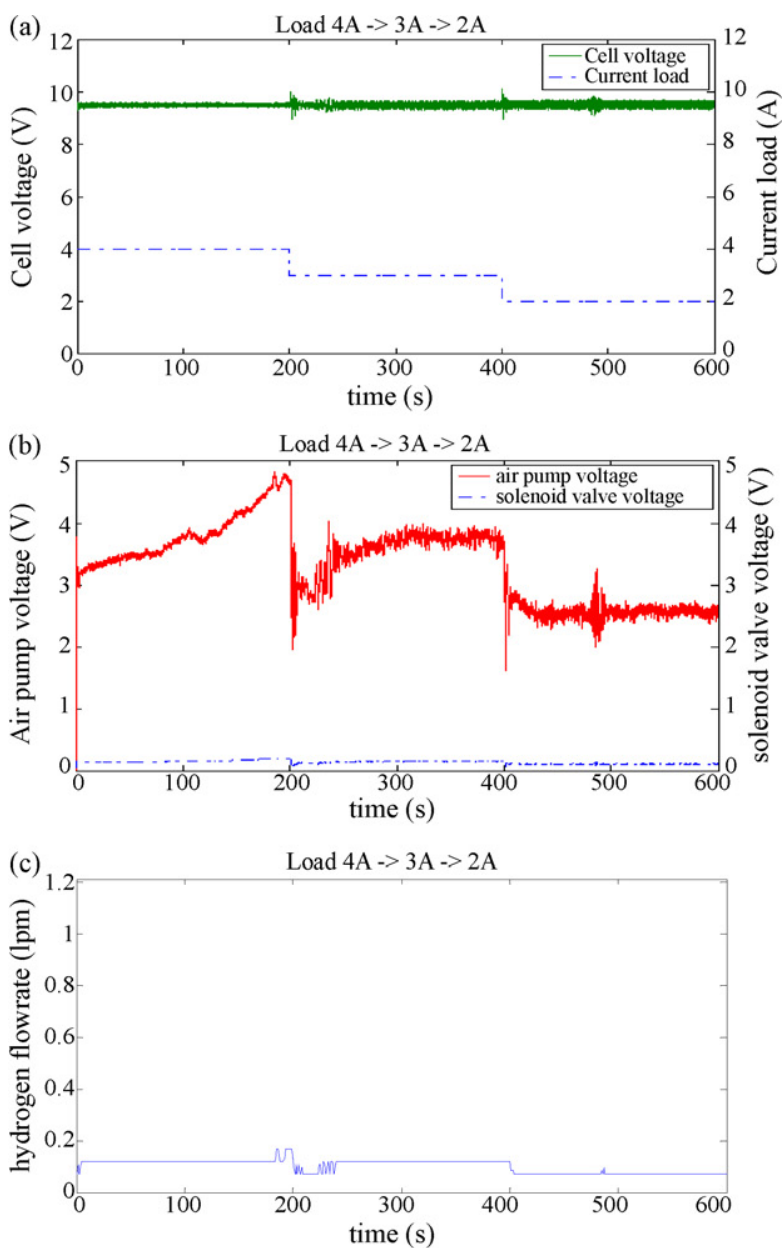

(d)

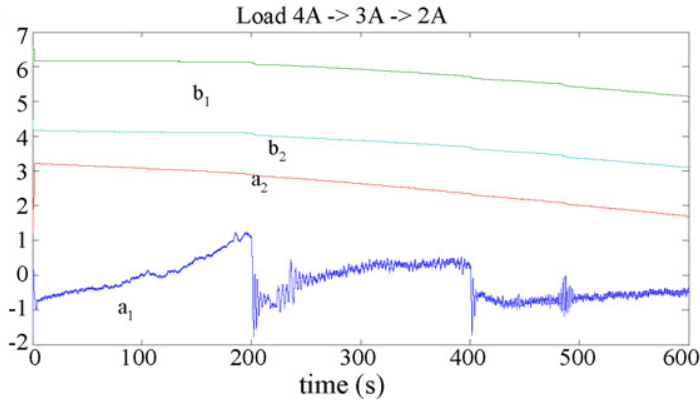

Fig. 17. (a) Adaptive control of cell voltage (solid curve) under the current command (dashed line), (b) the control voltage of air pump and solenoid valve, and (c) the corresponding parameters.

displayed in Fig. 17(c), and the estimation curves of the system parameters are illustrated in Fig. 17(d).

Compared to the continuous hydrogen supply at $1.2 \mathrm{LPM}$, the average flow rate of $0.13 \mathrm{LPM}$ during the first $200 \mathrm{~s}$ for the $4 \mathrm{~A}$ load accounts for a reduction of $89.9 \%$ hydrogen consumption. During the next $200 \mathrm{~s}$ for the $3 \mathrm{~A}$ load, the hydrogen consumption is reduced to $90.6 \%$ at the average flow rate of $0.114 \mathrm{LPM}$, and during the last $200 \mathrm{~s}$ for the $2 \mathrm{~A}$ load, $94 \%$ hydrogen is saved at the average flow rate of $0.087 \mathrm{LPM}$. At the transition of load variation, the cell voltage experiences an apparent oscillation, but settles quickly within a few seconds due to the robustness of adaptive control. Due to the regulation of cell voltage by the hydrogen flow rate, even though much
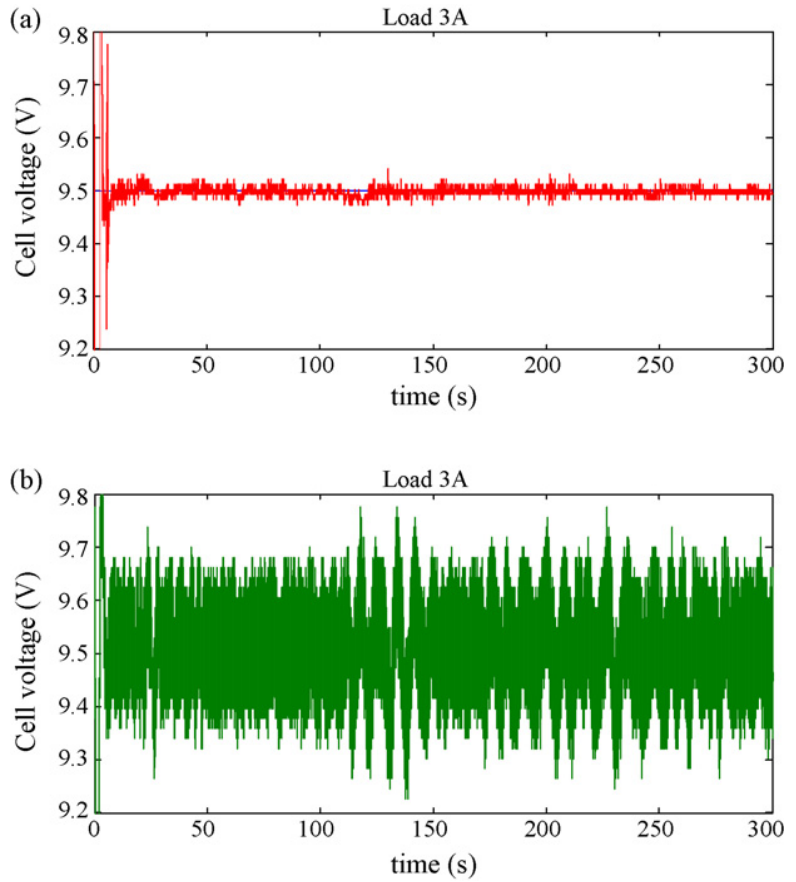

Fig. 18. Cell voltage under (a) an excessive supply (1.2 LPM) and (b) economic supply (0.12 LPM) of hydrogen.

hydrogen is saved, the amplitude of the sustained oscillation of cell voltage is much greater than that under an excessive supply of hydrogen. Fig. 18(a) shows the well-controlled cell voltage by an excessive supply of hydrogen of 1.2 LPM at the $3 \mathrm{~A}$ load, but Fig. 18(b) shows a heavier oscillation of cell voltage as the hydrogen is adjusted economically at 0.12 LPM by the rapid parameter adjustment of the adaptive controller.

In summary, from the above experiments, when the stoichiometric ratio of hydrogen and oxygen is larger than 2, i.e., the hydrogen is oversupplied, both the cell voltage and current can be controlled by the air-flow rate with only minor oscillations. When the oxygen or air is oversupplied and in contrast the hydrogen is supplied in an economic mode by the adaptive control law, both the cell current and voltage regulated by the hydrogen flow rate present larger oscillations. Table 3 summarizes the qualitative description of the resulting oscillation of cell outputs to the under- or over-supply of hydrogen. However, such oscillations can be suppressed by a proper choice of DC/DC converter. In short, the proposed model reference adaptive strategy results in a robust performance to the parameter variation at different power demands.

Table 3

Qualitative analysis of cell outputs

\begin{tabular}{llll}
\hline Input flow & Stoichiometry of $\mathrm{H}_{2} / \mathrm{O}_{2}$ & Cell output & Oscillatory \\
\hline Air & $>2$ & Current & Minor \\
Air & $>2$ & Voltage & Minor \\
Hydrogen & $<2$ & Current & Medium \\
Hydrogen & $<2$ & Voltage & Large \\
Air + hydrogen & $<2$ & Voltage & Large \\
\hline
\end{tabular}




\section{Conclusion}

Indirect model reference adaptive control has been successfully applied to a low-power PEM fuel cell. For use in control systems, the highly nonlinear, time-varying, distributed parameter fuel cell stack of complex electrochemical reactions and physics is approximated by a simple two-input two-output model that is described within subsystem blocks. These blocks describe the dynamic relationship between cell voltage and current outputs and the hydrogen and air-flow rate inputs. By including the dynamics of the air pump and solenoid valve, the corresponding transfer functions are identified off-line at certain operating points via a non-parametric frequency domain method. The model is subsequently reduced to an auto-regressive movingaverage model for on-line parameter estimation in an adaptive control loop. Experimental results show that the adaptive control is effective in regulating cell current and voltage by adjusting air and hydrogen flow rates in response to fuel cell and external power demand perturbations. On-off control of the hydrogen valve is shown to reduce fuel consumption, which increases system efficiency. It is noteworthy that the successful regulation of cell voltage by manipulation of the air pump and hydrogen valve may relieve DC/DC converters of demanding requirements for regulating fluctuating cell voltage. Nevertheless, the model reference adaptive control is applied under restricted conditions of operation in this research; it is necessary to make more effort toward its robustness and generality to a class of fuel cell systems. In addition, it is an important issue to include the water and thermal management in future research to monitor and control the humidity and temperature of reactants and the membrane so that the fuel cell can operate in a safe, efficient, and robust way with the proposed control strategy. It is expected that the proposed adaptive control can be easily extended to more complex multivariable control problems when more system states are to be regulated, and could be applied to stationary and transportation systems, as well as low- and high-power fuel cell applications.

\section{Acknowledgments}

The authors would like to thank Delta Electronics ${ }^{\mathrm{TM}}$ for providing the portable PEMFC system and Mr. H.P. Chang in the Chung Shan Institute of Science and Technology (CSIST) for his technical support for this paper.

\section{References}

[1] M.A.J. Cropper, S. Geiger, D.M. Jollie, J. Power Sources 131 (2004) 5761 .

[2] K. Astrom, E. Fontell, S. Virtanen, J. Power Sources 171 (2007) 46-54.

[3] Y. Shao, G. Yin, Y. Gao, J. Power Sources 171 (2007) 558-566.

[4] F. Mueller, J. Brouwer, S.G. Kang, H.-S. Kim, K.D. Min, J. Power Sources 163 (2) (2007) 814-829.

[5] J.T. Pukrushpan, A.G. Stefannopoulou, H. Peng, IEEE Control Syst. Mag. (2004) 30-46.

[6] M. Ceraolo, C. Miulli, A. Pozio, J. Power Sources 113 (2003) 131-144.

[7] J. Golbert, D.R. Lewin, J. Power Sources 135 (2004) 135-151.

[8] P.R. Pathapati, X. Xue, J. Tang, Renew. Energy 30 (May) (2005) 1-22.

[9] Y. Shan, S.Y. Choe, J. Power Sources 158 (1) (2006) 274-286.

[10] K.D. Min, J. Brouwer, J.S. Auckland, F. Mueller, G.S. Samuelsen, Dynamic simulation of a stationary PEM fuel cell system, in: Proceedings of the 4th International Conference on Fuel Cell Science, Engineering and Technology. June 19-21, 2006, Irvine, CA, ASME Paper FC200697039.

[11] A. Paradkar, A. Davari, A. Feliachi, T. Biswas, J. Power Sources 128 (2004) $218-230$.

[12] J.O. Schumacher, P. Gemmar, M. Denne, M. Zedda, M. Stueder, J. Power Sources 129 (2004) 143-151.

[13] F. Jurado, J.R. Saenz, IEEE Trans. Energy Convers. 18 (June (2)) (2003) 342-347.

[14] M. Tekin, D. Hissel, M.C. Pera, J.M. Kauffmann, J. Power Sources 156 (1) (2006) 57-63.

[15] C.H. Woo, J.B. Benziger, Chem. Eng. Sci. 62 (4) (2007) 957-968.

[16] R.T. Meyer, S. Revankar, A survey of PEM fuel cell system control models and control developments, in: Proceedings of FuelCell06: The Fourth International Conference on Fuel Cell Science, Engineering and Technology. Irvine, California, June 19-21, 2006, Paper No. 97030.

[17] R.N. Methekar, V. Prasad, R.D. Gudi, J. Power Sources 165 (1) (2007) 152-170.

[18] Y.P. Yang, F.C. Wang, H.P. Chang, Y.W. Ma, C.W. Huang, B.J. Weng, J. Power Sources 164 (10 February (2)) (2007) 761-771.

[19] F.C. Wang, Y.P. Yang, C.W. Huang, H.P. Chang, H.T. Chen, J. Power Sources 164 (10 February (2)) (2007) 704-712.

[20] R.F. Mann, J.C. Amphlett, M.A.I. Hooper, H.M. Jensen, B.A. Peppley, P.R. Roberge, J. Power Sources 86 (2000) 173-180.

[21] S. Yerramalla, A. Davari, A. Feliachi, T. Biswas, J. Power Sources 124 (2003) 104-113.

[22] J.M. Correa, F.A. Farret, L.N. Canha, An analysis of the dynamic performance of proton exchange membrane fuel cells using an electrochemical model, in: IECON'01, The 27th Annual Conference of the IEEE Industrial Electronics Society, 2001, pp. 141-146.

[23] M.A.R.S. Al-Baghdadi, H.A.K.S. Al-Janabi, Renew. Energy 32 (7) (2007) 1077-1101.

[24] G.F. Franklin, J.D. Powell, A. Emami-Naeini, Feedback Control of Dynamic Systems, 5th edition, Pearson Prentice Hall, 2006.

[25] R. von Helmolt, U. Eberle, J. Power Sources 165 (2007) 833-843.

[26] G.C. Goodwin, K.S. Sin, Adaptive Filtering Prediction and Control, Prentice-Hall, Englewood Cliffs, NJ, 1984. 